\title{
Nanotechnology and future applications of graphene in the construction of flexible screens as a component of the scenography
}

\author{
Aya Mohamed Kamal EIDean Amean
}

Lecture -Faculty of fine arts at Alexandria University

ayaMohamed.Kamal@alexu.edu.eg

\begin{abstract}
$\underline{\text { Abstract }}$
Since the beginning of the nineties, human civilization has introduced many modern and advanced industries, and it has become the age of technology, and it seems that we will talk about nanotechnology, which is an industry that depends on materials whose dimensions are measured in nanometers, depending on the application of applied concepts of natural sciences ( a micro levels), by creating structures and systems with properties and functions that are controlled at the atom level to produce new materials capable of dealing with particles of materials.

nanotechnology has been widely used in the field of many engineering industries, and this technology has been used to manufacture graphene, which consists of a single carbon atom bonded with other atoms in the form of repeating hexagonal patterns with a thickness of nearly a million times less than the thickness of ordinary paper, making it appear as a two-dimensional material.

One of the properties of graphene is its extreme strength, and it is also one of the emerging options available for alternatives to LED screens, which enables us to reduce costs and provide flexible and transparent conductive materials, in addition to being non-reflective, and because graphene is very strong and thin, it can be folded without To be broken, when searching for new forms and materials to be reformulated in a way that changes their functions and use, whether, at the level of basic sciences or future applications of human sciences, it was noted that graphene and the applications based on it in the industry are the optimal axes to talk about.
\end{abstract}

\section{Introduction}

Recently, many attempts have been made to develop designs for theatrical performances, not only moving the scenography elements but also moving the viewing audience in proportion to the movement of the screen as one of the scenography elements, and it seems that when looking for a way to make screens of large sizes, flexible, transparent, durable, strong, and a good conductor of current Graphene is one of the newly emerging materials available to obtain alternatives that enable us to reduce costs and 


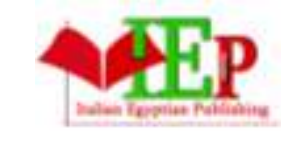

ISSN: 2735-4342
INTERNATIONAL JOURNAL OF

MULTIDISCIPLINARY STUDIES IN ART AND

TECHNOLOGY

VOLUME 1, ISSUE 1, 2018, 20-29.

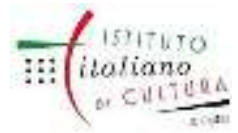

www.egyptfuture.org/ojs/

provide conductive materials based on

nanotechnology in their manufacture,

(graphene is a material consisting of carbon molecules, one atom of Carbon atoms are bound together in repeating hexagonal patterns with a thickness less than a million times the thickness of ordinary paper, making it appear as a two-dimensional material), and this material has the previous qualities in addition to being non-reflective, and because it is very strong and very thin, it can be folded without breaking, making it very suitable for the foldable electronics that will soon be available in the market, and may become one of the most important elements of theatrical scenography.

\section{$\underline{\text { Materials \& Methods }}$}

Nanotechnology

Nanoparticle applications

Nanotechnology and graphene industry

Graphene industry applications

Graphene and flexible screens industry

Screens as an element of scenography

Graphene screens

Ballet Crane dance

The Han Show Theater

Results

\section{Research problem:}

How to exploit nanotechnology and graphene in the manufacture of flexible screens of huge sizes as one of the elements of scenography and control its movement during the theatrical performance in an ideal way to achieve an immersive experience for viewers in large sizes and characterized by its durability and stability even with the presence of many installations without losing this movement viewer immersive sense because of its weight.

\section{Research Objective:}

Prove that technological sciences are inseparable from human sciences and clarify

the extent to which they are related and serve each other

\section{$\underline{\text { Research methodology: }}$}

An analytical survey study that depends on monitoring and analyzing the extent of technological progress and its service to all human fields and rooting the idea of scientific theater

\section{$\underline{\text { Research procedures: }}$}

\section{Nanotechnology:}

When human civilization reached a new age since the beginning of the nineties, which is the age of nanotechnology, the slogan of this technology was the manufacture of materials whose sizes are measured in nanometers that have modern properties and are extremely small with amazing capabilities, based on the application of theoretical concepts of natural sciences by searching behind infinitesimal levels By creating structures, systems, and devices with unique characteristics and functions that are controlled at the atom level to produce new materials capable of dealing with particles of matter, and is concerned with creating new techniques and means whose dimensions are measured in 


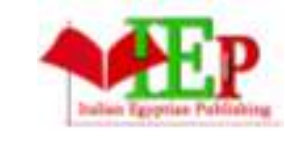

ISSN: 2735-4342
INTERNATIONAL JOURNAL OF

MULTIDISCIPLINARY STUDIES IN ART AND

TECHNOLOGY

VOLUME 1, ISSUE 1, 2018, 20-29.

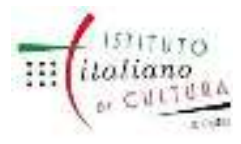

www.egyptfuture.org/ojs/

nanometers, which equals one-thousandth of a micrometer, or one-millionth of a millimeter. These dimensions are much smaller than the dimensions of bacteria and a living cell. So far, this technology is not related to biology but is concerned with the properties of materials that lead to new electromagnetic and optical phenomena for the material whose size is between the size of the molecule and the size of the visible solid.1 Some countries have launched studies on this technology, and other countries have made research centers, studies, and universities Dedicated to nanotechnology, and assigned a group of distinguished experts to study this technology

The nano-industry has entered into application in a group of commodities that use nano-particles of the oxide of its types,

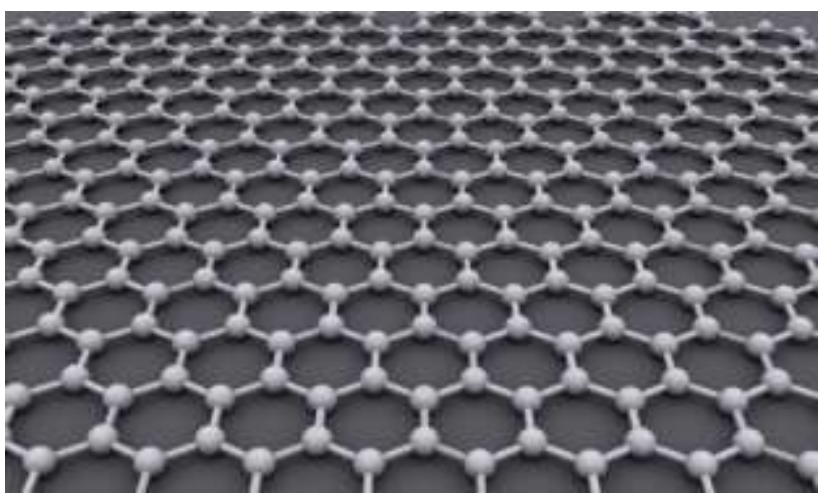

all UV rays and the ointment at the same time remains transparent and is used in some antistain clothes 3, Nanotechnology has been widely used in the field of engineering industries, for example, raw materials can be converted into materials with specifications of greater engineering quality or with extreme accuracy by creating Changes in the physical properties of its constituent molecular sizes. "aluminum, titanium, and others" Especially in cosmetics and ointments anti-rays It blocks Thus, its optical properties are affected by its mechanical properties such as hardness, Durability, It is ten times more rigid than steel and has the ability to save energy in addition to its ability to fold and form, and the properties of traditional polymers can be changed by using nanoparticles in the materials. 


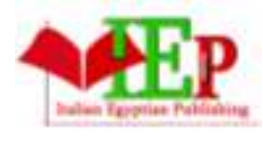

ISSN: $2735-4342$
INTERNATIONAL JOURNAL OF

MULTIDISCIPLINARY STUDIES IN ART AND

TECHNOLOGY

VOLUME 1, ISSUE 1, 2018, 20-29.

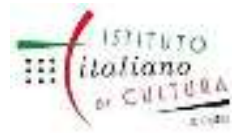

www.egyptfuture.org/ojs/

The new ones, which may be used as lightweight alternatives to metals, and by this process, the initial specifications of the materials can be improved, in addition to reducing the weight and increasing the stability properties and other requirements to acquire new properties. From different applications and fields, such as what the United States aspires to serve military purposes (making a military suit that makes the wearer invisible by reversing the view in the background) 4 , which are related to materials science, and can also be employed in the fields of architecture, engineering or Even in the construction of body armor, it exhibits exceptional strength and unique electrical and thermal properties.

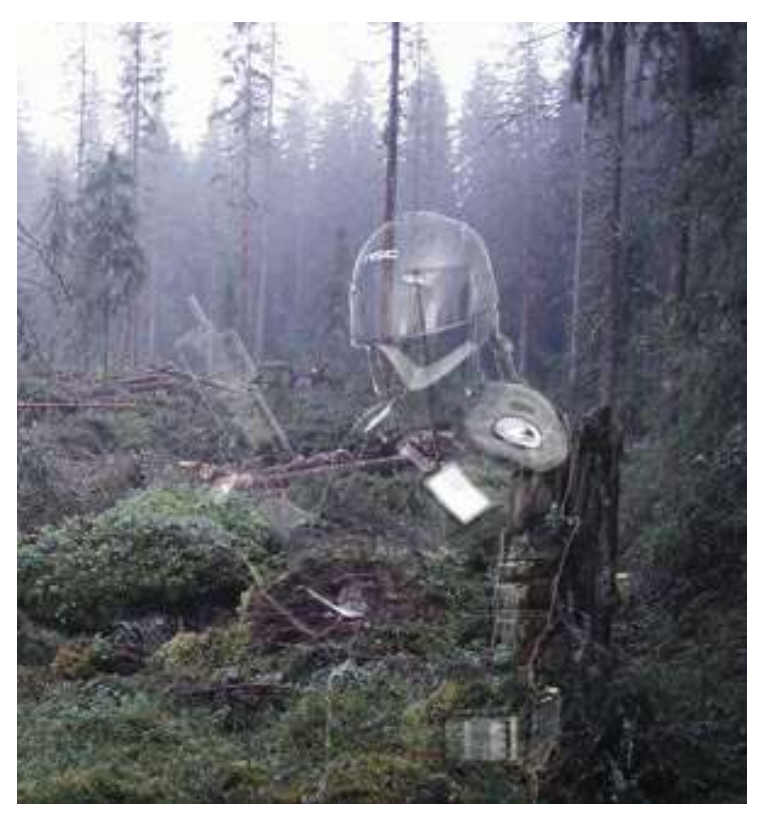

\section{Nanotechnology and graphene industry:}

This technology has been used to manufacture graphene, which consists of a single atom of carbon atoms bonded with other atoms in the form of repeated hexagonal patterns with a thickness less than the thickness of ordinary paper by nearly a million times, making it appear as a twodimensional material

Before the isolation of single-layer graphene in 2004, it was theoretically believed that twodimensional compounds could not exist due to thermal instability when separated. They are extremely light materials, 200 times stronger than steel, yet amazingly flexible, as well as being transparent and conductive. Good for electricity and heat.5

\section{Graphene industry applications:}

One distinct property of graphene is its extreme strength. Given the strength of carbon bonds of $0.142 \mathrm{Nm}$, it becomes the strongest material ever discovered and is also very light at 0.77 milligrams per square meter (1 square meter of paper is about 1,000 times heavier). It is often said that one sheet of graphene is sufficient to cover an entire football field, that would weigh less than one gram, 6

\section{Graphene and flexible screens industry}

Graphene is one of those emerging options available for alternatives to LED screens that enable us to reduce costs and provide flexible and transparent conductive materials as well as non-reflective, and because graphene is very strong and thin, it can be folded without breaking, making it very suitable for electronics The foldable screen, which will soon be available in the market, thus provides a way to make screens of large sizes, flexible, transparent, durable and strong, and conducts 


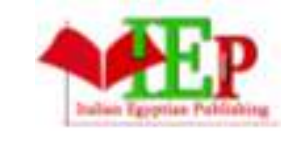

ISSN: 2735-4342
INTERNATIONAL JOURNAL OF

MULTIDISCIPLINARY STUDIES IN ART AND

TECHNOLOGY

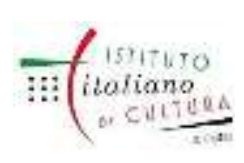

www.egyptfuture.org/ojs/ good electrical current, which qualifies it to become one of the most important elements of theatrical scenography. After several attempts, researchers at Samsung and Sungkyunkwan University in Korea were able to produce chips of graphene that could be connected to a computer to turn them into a flexible touch screen in the size of a large TV. ${ }^{7}$

\section{Screens as one of the elements of scenography:}

The scenography is all the elements responsible for the final theatrical image that the audience sees during the theatrical performance which is represented in the scenes, lighting, tricks, effects, and extends to the theatrical architecture, with all that it contains the audience's seats and the theatrical display area.

The idea of using screens in theatrical performances is not new, but it received great attention from Josef Svoboda who is considered one of the most influential scenographers in the late twentieth century he used to combine screens and live events on the stage, He also sought to employ the screen in theatrical decoration within the scenography of the show.

\section{Graphene screens:}

The connection between technology and theater is one of the most known facts. Although each of them has its own characteristics, historical backgrounds, and countless advantages, which must interact with each other to form the final image of theatrical performances in the perfect image.

In recent years, modern technology in many fields such as photography, montage, tricks and effects, 3D computer graphics, and live broadcasting, 3D stereoscopic display, hologram technology, motion capture, and the possibility of embodying live characters in the air using a medium (water, smoke, screen), so the number of possibilities that can be employed is endless.

At a cost ranging from a few simple pounds to millions of dollars, scenography relied on the use of large screens as one of the most important elements of scenography at present, if not the main element, especially in musical performances.

Modern designs of scenography depend on technical development and breaking were known rules and laws as a result of great technological efforts that became a given to subject technology to theatrical performances with The vision aspect and considering the performer the living element in the theatrical space and addressing the eye and the ear together, and we have to acknowledge an important fact, which is that technology is just a means and not a goal or an end in itself and that the director if he has a simpler means To achieve his artistic vision, he should use it. 
The presence of television or reflective screens on the stage may reduce the focus of the viewer or separate him from the presented event, and the size and color of these screens may be a factor defect the scenography of the show and thus confuse the viewer unless it is properly exploited to serve the purpose of the show, but the use of Screens have encountered many problems, some of which have been dealt with, and some have not yet been resolved. Therefore, it was the exploitation of technology as a means in serving the theatrical performance that presented new horizons for creativity to make the theater able to compete with other artistic means such as television and cinema, provided that being aware of the privacy of the theater,

It is responsible for the direct encounter between the actor and the spectator, it contains all the arts (cinema, video, music, dance, singing, and graphics) and makes them additional elements that serve the director's vision.

If the technology can serve scenography by making screens of graphene instead of normal screens to provide the appropriate size and weight, this provides complete flexibility in the design, as we can control the shape and size of the screen and the possibility of using it in a variety of ways that were not used before, and on The director always asks himself the important question: What does technology add to this scene?

\section{The Crane dance}

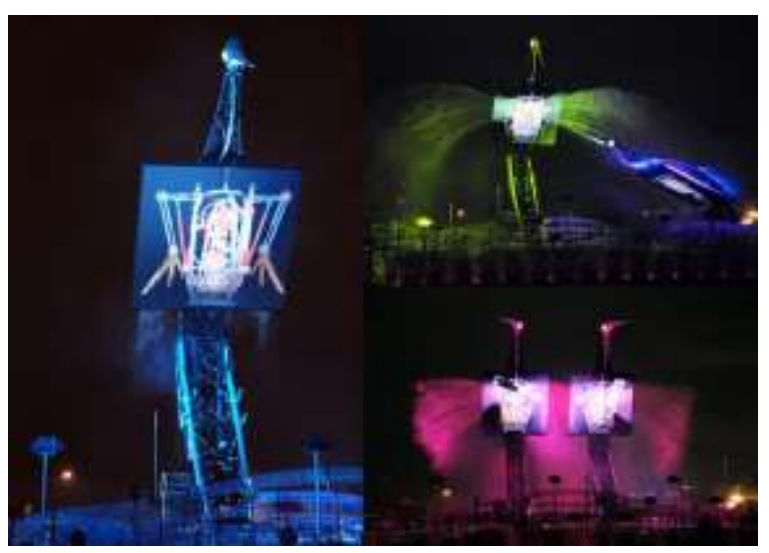

Since the use of screens is one of the most important elements of scenography until now, we find in front of us some models that were presented recently, which bear many problems that affect the designer's thinking about the possibilities that must be available to complete the design,

The most important of these problems were:

- Size and weight of design elements, including huge screens.

- Shape and control.

- Strength, toughness, and endurance.

- The conductivity of electricity and energy saving.

- Resistant to wind and weather factors.

In 2011, the Genting Group presented a large-scale theatrical performance to open a resort on Sentosa Island in Singapore. Designed by Mark Fisher, titled (The Ballet Crane Dance), and the idea here was summed up in the possibility of structuring the huge moving birds in the design of the theatrical performance using a pair of mechanical birds 150 feet high dancing with mechanical cranes, and the design was based primarily on 


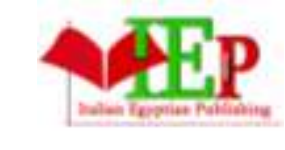

ISSN: 2735-4342 the use of giant screens and units The lighting and sound made this resort a success and fame. ${ }^{8}$. This design contains mechanical models that represent the largest moving creature in the world. Each of the two birds weighs approximately 80 tons, equivalent to 10 African elephants powered by a diesel engine equivalent to 5000 horses. With this size, these two birds have the ability to move more lightly and accurately ${ }^{9}$, in this type of display, the screens used can be replaced with others made of graphene material to save weight and cost.

The weights of the elements used in some designs may be one of the hindrances to it. Some designs depend on the movement of the screen during the theatrical performance, mechanical movements.

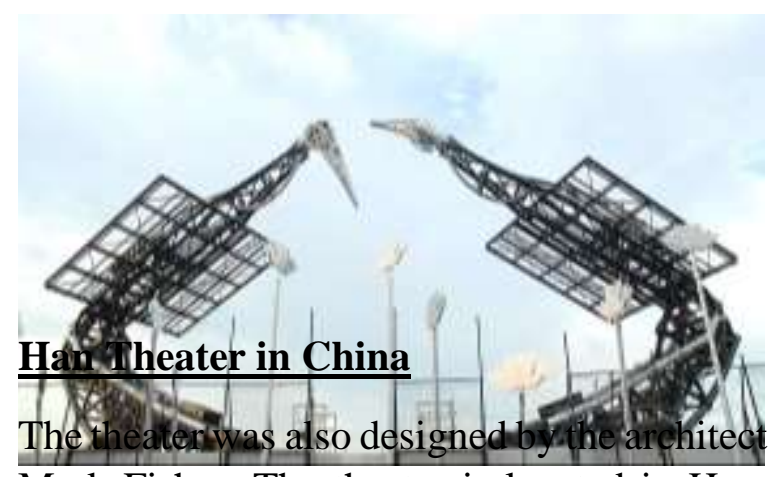

Mark Fisher. The theater is located in Han, China. The exterior architectural form is inspired by the traditional image of Chinese lamps.
The theater contains 2000 seats characterized by the ability to move and rise during the theatrical performance or to rotate and descend vertically.

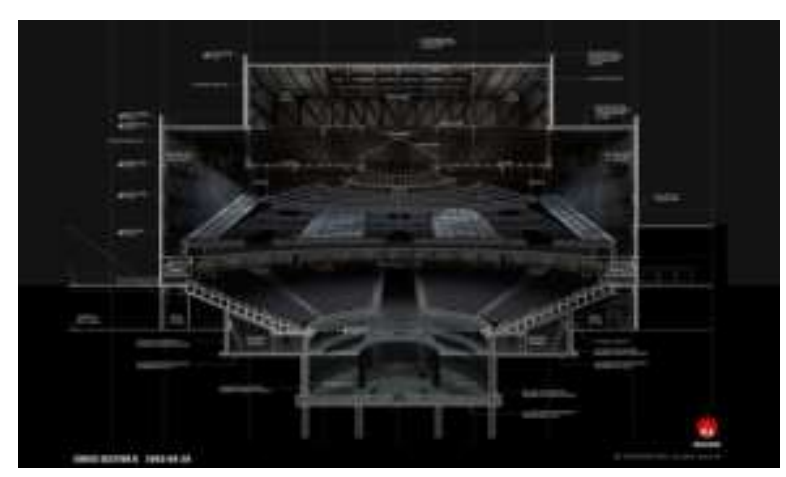

The special effects allow the performers to fly above the stage, up and down, using intersecting steel rings suspended around the stage. The theater performance area is located in the middle with a depth of 8.7 meters filled with water, in addition to three robotic arms that carry huge LED screens that rotate 360 degrees around themselves. Through an automatic control system, its dimensions are 7 meters $x 11$ meters and weigh 8 tons. The thickness of the screen is $8 \mathrm{~mm}$ and it was specially made for this theater without being bound by the commercial specifications of the manufacture of regular screens. The idea of getting rid of gravity became the driving element for these screens when they were replaced by graphene screens that are lighter and flexible we save a lot of energy because the energy used to move the screens is less due to the lighter weight. 
From the picture in front of us, the audience seating area, the water area, and the huge arms of the screens show the movement of the huge screens and their relationship to the audience seating areas. ${ }^{10}$

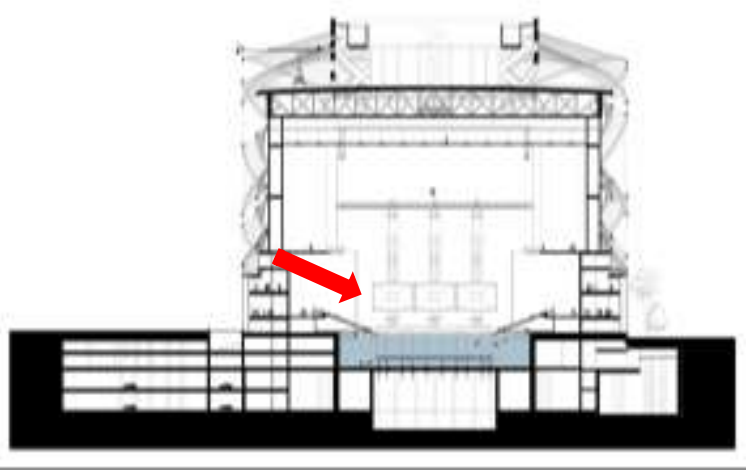

The screens in the shows contain many parts next to each other, and this is what we are talking about in an attempt to reduce the installations of the screen to simple and uncomplicated structures, the existing image

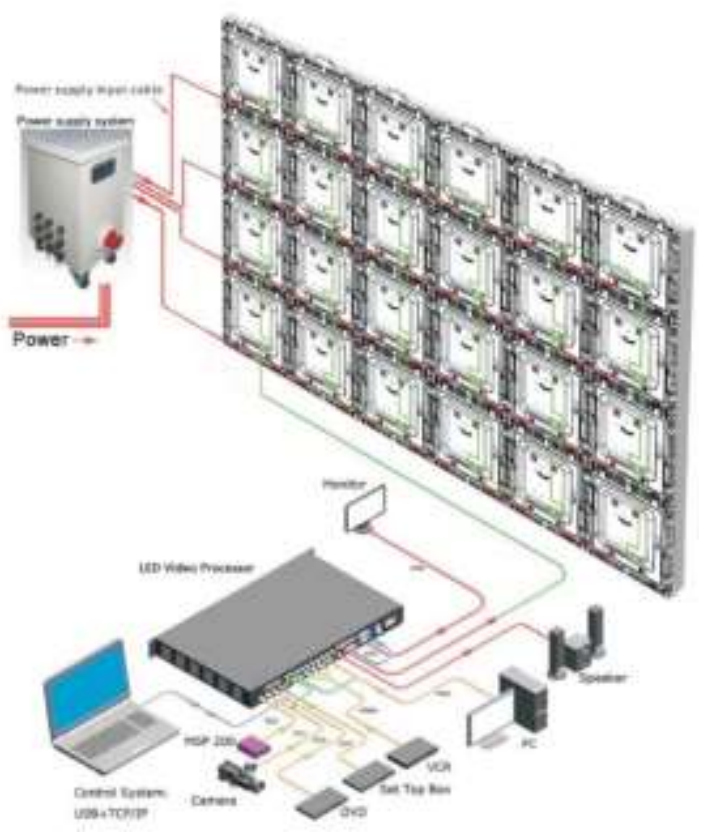

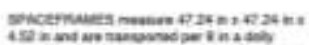

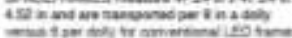
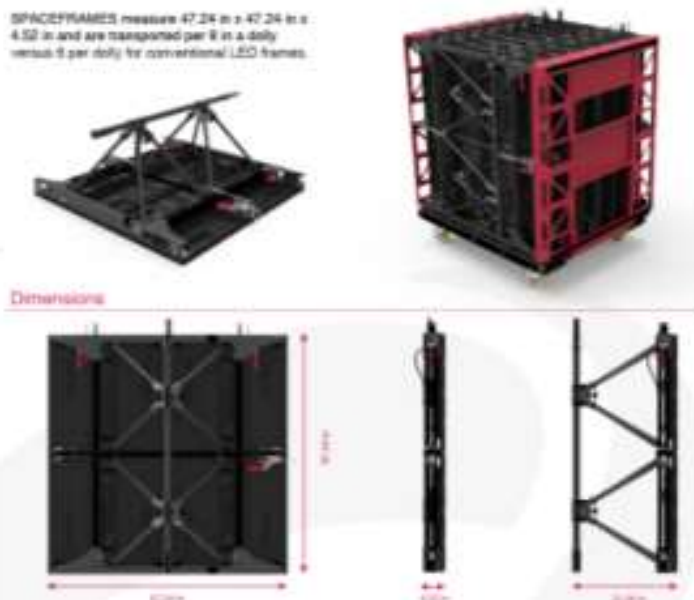

expresses the installations for connecting the screen divided into parts.
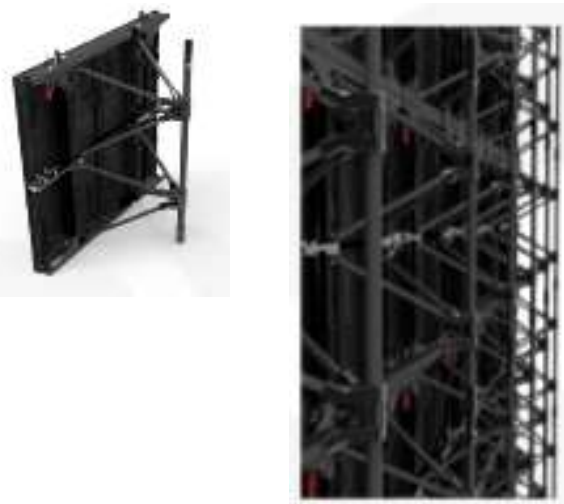

Attempts continued to reduce and reduce all the installations of the screen after that to save transportation and storage space until it reached the SPACE FRAME technology based on carbon tubes. 


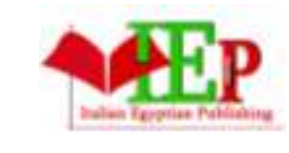

ISSN: $2735-4342$
INTERNATIONAL JOURNAL OF

MULTIDISCIPLINARY STUDIES IN ART AND

TECHNOLOGY

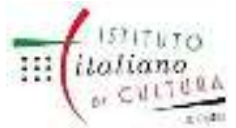

www.egyptfuture.org/ojs/

\section{Conclusion:}

Material technology scientists and specialists were able to invent materials with capabilities that were not exploited before, they searched for new forms and materials that can be reformulated to serve humanity, and those interested in exploiting these materials in various human sciences with flexibility and simplicity to support in reducing the rate of consumption Electricity and environmental protection.

\section{Results:}

Technical development is not limited to mechanical developments only but extends to materials technology, which changes its functions and uses, whether at the level of basic sciences or future applications of human sciences, thus opening new horizons for technology in various human sciences to create new visions that were not clear before.

\section{Recommendations:}

Nanocomposites are a double-edged sword, some of them are stable compounds that can be controlled and others that are not stable and uncontrollable, and we cannot determine the number of risks resulting from this technology and its relationship to lifestyles in developing countries and its ability to mutate or transform into destructive substances and Dangerous due to many reasons, including misuse, climatic conditions, and means of disposal of the waste of these materials, which may cause serious diseases over long periods of time, in addition to their impact, which may be devastating to microorganisms, and thus be one of the causes of destroying the ecological balance, in addition to the uses It is necessary to deal with this technology with more caution and to continue conducting its own research to ensure everything that surrounds it and how we use it.

\section{Reference:}

1-http://www.egyres.com/articles

2-https://seanduke.com/category/nanotechnology/

3- http://www.nanowerk.com/nanotechnology-applications.php

4-http://www.graphene.manchester.ac.uk

5-Scientific Background on the Nobel Prize in Physics 2010 G R A P H E N E compiled by the Class for Physics of the Royal Swedish Academy of Sciences

6- Nature (2015) doi:10.1038/522268a | Published online 1 Aug 2015 | English article

7-https://www.technologyreview.com

8- http://entertainmentdesigner.com

9- http://laiyewseng.com.sg/crane_dance_resorts_world_sentosa.html

10-http://edunloaded.com/fun-activities-for-the-family/crane-dance-sentosa/\#

11-http://www.itsliquid.com/han-show-theatre-stufish.html 


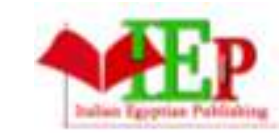

ISSN: 2735-4342
INTERNATIONAL JOURNAL OF

MULTIDISCIPLINARY STUDIES IN ART AND

TECHNOLOGY

VOLUME 1, ISSUE 1, 2018, 20-29.

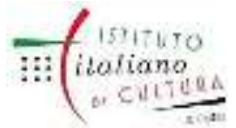

www.egyptfuture.org/ojs/

12-http://vic.sina.com.cn/news/27/2014/0517/57515_2.html\#page_pic

13-http://www.taittowers.com/projects

14-http://plsn.com/current-issue/49-features/16376-the-han-show-theatre.html

15-http://www.thehanshow.com

16- The Science and Engineering of Materials, Sixth Edition, Authors Donald R. Askeland, Pradeep P. Fulay, Wendelin J. Wright, Publisher, Global Engineering: Christopher M. Shortt, Library of Congress, Copyright 2010 Cengage Learning, Inc.

Received: February 15, 2018

Accepted: April 20, 2018 